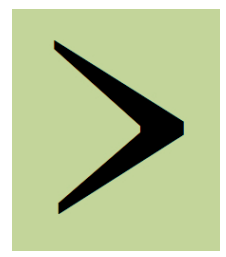

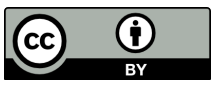

Licensed under a Creative ISSN 2399-6714

Volume $1,37-49$

DOI: $10.2218 /$ pihph.1.2016.1692
Commons 4.0

International

License

\title{
Historical phonology and morphology in the nineteenth century: abstractness vs. empiricism
}

\author{
ANDRÁs CSER \\ Pázmány Péter Catholic University
}

\begin{abstract}
In the first half of the nineteenth century comparative and historical linguistics focused mainly on morphological structure. Although important phonological discoveries were made, phonology played a subsidiary role to morphology. What could be called the models of language were all theories of morphology. These speculations were targets the Neogrammarians attacked vigorously, mainly in the spirit of uniformitarianism. Phonology was different in terms of abstractness. Sounds were treated in a superficially abstract manner, but this was based on the phonetically imprecise littera-tradition, the emphasis on correspondences, the focus on dead languages, and the impact of the Indian tradition. The Neogrammarians, by contrast, strove to make phonology more phonetic and more rigorous and, paradoxically, earned the contempt of their opponents for introducing a different kind of abstractness by reconstructing a segment not attested in unchanged form in any of the Indo-European languages. In turn, while the Neogrammarians admitted that de Saussure's analysis in the Mémoire is highly logical, they dismissed it as lacking sufficient empirical motivation. It appears that the argument reminded them of the analyses of the previous generation, and de Saussure's formulation, which they found unduly abstract, was superficially just the kind they wanted to purge linguistics of at last.
\end{abstract}

\section{Introduction}

This paper looks at the transition from the framework of the comparative and historical linguistics of the early and mid-19th century to that of the later $19^{\text {th }}$ century from two interrelated aspects, both essential to this transition, which is commonly referred to as the Neogrammarian revolution. One of these aspects is how phonology and morphology related to each other, or more precisely how the study of sounds and sound changes on the one hand, and how morphology on the other, related to each other. The other aspect is how abstraction and 
fact-oriented empiricism related to each other. These questions are interesting primarily because important shifts took place in the 1870's in both respects.

The discussion is by and large chronological, which means I will first look at what phonology and morphology were like before the 1870 's - that is, in what is often called the Paleogrammarian period. I will then discuss what was new in the Neogrammarian approach. This, of course, is not uncharted territory; the Neogrammarians' work and their achievements are well known, not just the exceptionlessness of sound change, not just their preoccupation with analogical change, not just their adoption of the uniformitarian principle - and there is a vast amount of literature on them, such as Murray (2015), an excellent chapter on $19^{\text {th }}$ century historical phonology, and Morpurgo Davies (1998), a superb monograph on $19^{\text {th }}$ century linguistics, just to name two outstanding contributions to the topic. Nevertheless, while much about the Neogrammarians is common knowledge, certain important aspects of their work and their achievements seem to be somewhat overlooked or at least not fully appreciated in the conventional wisdom.

One issue that I would like to highlight is that the relation between morphology and phonology and their respective roles in the comparative and historical investigation of languages was conceived of differently by the Neogrammarians and their predecessors. Furthermore, while it is again well known that the Neogrammarians represented a positivistic approach to the study of language in which a methodical assessment of the facts was a precondition to any generalisation, on certain occasions they were reproached for removing their reconstructions from immediate similarity to attested forms, that is, they were reproached for positing forms that were considered abstract. I will also briefly discuss the way the Neogrammarians related to de Saussure and how the issue of empirical data vs. system-based abstraction played a central role in their aversion to his reconstruction of the Proto-Indo-European vowel system.

\section{The Paleogrammarians}

The way sounds and sound systems and sound changes were studied between 1800 and the 1870's looks, at first sight, abstract, or - so to speak - phonological in the sense that phonetic details were disregarded, actually unknown or not sufficiently known in many of the cases that were discussed by the linguists and philologists of the period, but, at the same time, grand overarching schemes and coherent patterns are not infrequently found in these discussions. It is enough to 
think of two famous examples from the two opposite ends of the Paleogrammarian period to illustrate this.

One is Jacob Grimm's (1821) renowned Kreislauf, which encompasses what is now called 'Grimm's Law' as well as the High German Consonant Shift. The Kreislauf is a beautifully consistent pattern of changes in which the obstruents undergo change in a regular, repeating fashion, on both occasions in the same direction, the change involves the same manner categories, and place never changes. Now, as Murray $(2015,17)$ very aptly says,

[T] he beauty and simplicity of Grimm's analysis is entirely dependent on a high degree of - dare we say, phonological - abstractness and a striking absence of phonetic detail and accuracy.

This is indeed so: in Grimm's notation, for instance $P H$ denotes PIE [bh], and PGmc [f], as well as OHG [pf].

The other example is the PIE vowel system as presented by August Schleicher in his Compendium (1861). His system is again very simple and elegant: three base vowels $(i, a, u)$ with a first grade (ai, aa=ā, au) and a second grade (aai=āi, aaa=ā, aau=āu). At first sight this might look like something straight out of a paper on Particle Phonology or Government Phonology from the 1990's. But, of course, it is a simple adaptation of the ancient Indian (Paninian) gradation theory, which was established by the ancient Indian grammarians on the basis of the alternations going back historically to Ablaut.

What were the underlying roots of this approach to the sounds of language? Why is it that the study of sounds was more phonological on the face of it than phonetic? One reason was the inherent phonetic imprecision of the littera-tradition ${ }^{1}$ (Buchstabenlehre, Letter Theory), which was the inherited framework for the study of speech sounds (which is not the same as contemporary phonetics, a point I will come back to below). Units of this level of language had been described since antiquity as having three properties, (graphic) shape, (phonetic) value and name. Basically those sounds were regarded as linguistic units that could be represented graphically in a conventional way (this is what articulated sound originally means); clearly this approach does not really invite detailed phonetic observations.

Another reason was that sounds were largely studied in the framework of correspondences, which itself by nature invites a broader perspective and a search for a common denominator within a set of given sounds rather than their phonetic details. The regularity of the

\footnotetext{
${ }^{1}$ For an insightful current treatment see Lass (2016).
} 
correspondences that were discovered by Rasmus Rask and then placed into a wider context by Jacob Grimm was demonstrated convincingly, and that was the point, as in virtually all the discussions of sound changes found in the great comparative works. This point is very explicitly made in Pott $(1833,69)$, where it is explained that etymological correspondences are to be sought primarily, and phonetic similarities are not so important, although it is good to have them, if they happen to occur.

The third reason was that the vast majority of the languages that were studied in the period were dead languages, for which phonetic details were inaccessible. It goes without saying that there was simply no point in asking certain kinds of questions about phonetic details - it took some time for a methodology to be elaborated for sorting out pieces of information about the sound shape of dead languages. The fourth reason was the impact of the Indian tradition, which was in itself fairly abstract with sets of rules describing alternations such as gradation (mentioned above in the context of Schleicher's vowel system).

Last but not least it is the fact that works which were published in the early nineteenth century or the eighteenth century on what would now be called phonetics proper were simply not read very much by linguists. Murray $(2015,18)$ makes the point very emphatically that there is "no possibility of arguing that Grimm's thinking was the reflection of a generally underdeveloped science of phonetics. In fact, contemporary phoneticians were extremely critical" (viz. of his Kreislauf-analysis). And there are some quite extraordinary works that linguists should have read but did not. Murray highlights two authors, the Danish Jakob Bredsdorff, and the German Rudolf von Raumer. To name another one not generally known to linguists, there was Wolfgang von Kempelen, an outstanding polymath of the late eighteenth century, who was famous primarily for his automaton chess player (which was partly a hoax), but he also constructed a speaking machine with which he could synthesize speech sounds and word-sized chunks of articulated speech. He wrote a book about this speaking machine (Kempelen 1791) that describes the speech sounds found in the various European languages in great detail, and also discusses the workings of the speech organs as well as general issues of language with acumen and elegance of style. Although he published the book nearly simultaneously in German and French, his work remained completely unknown to linguists for some reason. Recently there has been some renewed interest in his work and even a few functioning replicas of his speaking machine were made, but he and his truly amazing book are 
not very often mentioned in histories of linguistics (Morpurgo Davies 1998 being an exception).

So far we have been looking at phonology, or more precisely the study of sounds and sound changes in the early and mid-nineteenth century. But this was not really the main focus of interest in the study of language. Pride of place was reserved for morphology rather than any other level of linguistic structure. It is no exaggeration to say that in this period, up to the 1870's, theories of language were theories of morphology - more precisely, evolutionary theories of morphology. The "models" of morphological change were greatly abstract in the sense that there was basically no empirical motivation for them and forms and structures were suggested for the proto-language (before Schleicher 1861 only implicitly) which were in no way attested in any of the languages that served as the basis of comparative work. Let us consider what these models looked like.

I shall take a cursory look at some of the most important authors of the period (and this is meant to be a representative, though very incomplete picture). Friedrich von Schlegel (1808, see also Morpurgo Davies 1998, 66-75) borrowed the idea of organicism from his contemporaries and applied it to language, specifically with respect to morphological structure. The languages he called organic were what we would call inflecting or fusional; the languages he called non-organic or mechanical were the ones we call agglutinating and isolating languages. He also made important claims about the origin of grammatical markers in the organic languages (affixes as well as internal modifications of the root - and it is the internal modifications, such as ablaut and even infixation that make these languages organic). He claimed that these grammatical markers literally sprouted from the roots, they grew out of the roots to express grammatical relations and had no other function. As time progressed, these organic grammatical markers tended to be lost at least to a certain extent, but languages would fundamentally not change their character, viz. being organic or non-organic.

By contrast, Schlegel's contemporary, Franz Bopp (1816 and 183352, see also Morpurgo Davies 1998, 129-136) gradually abandoned the organic idea and introduced a somewhat more formal method into the comparative morphological analysis of the then known Indo-European languages. He did a thorough analysis, a segmentation of the many forms in the inflectional morphology of the old Indo-European languages, starting with Sanskrit, and then tried to find correspondences to words. His fundamental assumption was that affixes derive from full words, original roots, which gradually attached to other roots and became their satellites, so to speak, and finally 
became parts of the larger word forms. As part of this, he also had the idea that every verb form included either explicitly or implicitly some form of the verb 'to be', which is actually an idea going back ultimately to Aristotle and represented in early modern times by the Port Royal grammarians. $^{2}$

The third important linguist of the period to mention at this point is August Schleicher, who was in many ways the most extreme representative of the Paleogrammarian ideas. In the introduction to his renowned Compendium (1861) he expounds the idea that the life of languages can be divided into two major periods, one of growth and one of decay, and the transition between the two is gradual. He claims that the period of the growth of language begins with an isolating stage, with no morphology at all. Then agglutinative morphology develops from the combination of roots with each other and the degradation of some of them into affixes. This agglutinating stage later develops into an inflecting stage, which is the most highly developed form that a language can attain, but only two kinds of languages are known to have attained it, viz. the Indo-European languages and the Semitic languages. These three successive stages (isolating, agglutinating and inflecting or fusional) all belong to the prehistoric period and they constitute development in this sequence, they constitute growth. But the period of decay then sets in, and languages begin to degrade. The two chief mechanisms of this degradation are sound changes and morphological change (analogical change). Schleicher also claims that the splitting of the proto-language into daughter languages, which in turn split further into yet other descendants and then into dialects, also belongs to the second, the historic period. This means that there is no divergent linguistic development in prehistory.

I hope that this cursory treatment of these three outstanding linguists of the early and mid-nineteenth century shows clearly enough the absolutely central role that morphology played in this period. As I mentioned earlier, up to the 1870's theories of language were evolutionary theories of morphology. This central role is underlined by the fact that phonology played a subservient role vis-á-vis morphology in comparative reconstruction as practiced in the period, and it is perhaps no great exaggeration to say that this was one of the greatest obstacles to the development of both the technical and the theoretical side of work. Let me take an example from Schleicher's work (also highlighted in Morpurgo

\footnotetext{
2 Bopp's morphology was also insightfully discussed in Paul Kiparsky's (1974) paper, which draws attention to the highly compositional morphology, with a strong emphasis on the semantic categories whose ruins, as it were, are still visible in the documented languages.
} 
Davies 1998, 265). He derived all the personal endings from personal pronouns, e.g. 2Sg Greek -eis, -si, -s, -thi, -tha as well as the related forms in the related languages from the reconstructed pronoun *tva. He did this in spite of the fact that the change from *tva to these suffixes (or at least to some of them) involved sound changes that were otherwise not attested at all. This did not seem to be a serious issue for him, however: as long as the functions matched (2Sg), he (like most other linguists of the period) was content to regard this as a valid etymological statement (a point nicely illustrated also in Kiparsky 1974 with similar data from Curtius 1877).

I hasten to add that it is somewhat unjust to single out this example from Schleicher because he was, in fact, still relatively strict about the regularity of sound changes compared to some of his contemporaries. In his Compendium he explicitly divides linguists into two groups, one that takes regularity seriously and one that does not - listing himself as belonging to the former. But the example just seen still represents the attitude prevailing in the period. And this is what I meant when I said that phonology played a role subservient to morphology: morphological and functional considerations could override considerations of phonological regularity, and this was not usually seen as a problem until the 1860 's and especially the 1870's.

\section{The Neogrammarians}

The tide began to turn in the 1860's and more spectacularly in the 1870 's with the Neogrammarians, a shift that had important long-term consequences. Already before 1870 some linguists such as Scherer were critical of the type of work in comparative linguistics that Bopp or Pott had been doing, and important sound laws were discovered, such as Grassmann's Law, which partly undermined their reconstructions. Also the tendency was for linguists to take what came to be called sound laws more and more seriously. And in the 1870's the Neogrammarians enter the stage.

Several points are important in this context. First of all, the study of sounds. As is well known, the Neogrammarians took phonetics much more seriously than their predecessors, but this was not because there was no serious phonetics before them but because there was a disconnect between phonetics and the work of the grammarians. It was pointed out long ago as a symptomatic fact that Eduard Sievers' Grundzüge der Lautphysiologie was published in 1876 as volume one of a series called the 'library of Indo-European grammars' (Bibliothek indogermanischer Grammatiken). That sound changes should be explained on the basis of the physiological mechanisms of articulation was an important principle for them, even if in its practical applications it 
did not always lead to lasting results. In general, one can say that the style and the tenor of the research they did was more empirical than that of the Paleogrammarians; they repudiated the traditional abstractness, and they tended not to use the quasi-algebraic notations seen earlier, (cf. Schleicher's system of PIE vowels, or Grimm's Kreislauf, for that matter.)

It is also worth noting that there was a rift between Brugmann, the young figurehead of the first generation of the Neogrammarians, and Curtius, his teacher and senior colleague, over two articles that Brugmann published in Curtius' journal in the latter's temporary absence (Brugmann 1876a, b). This rift is usually presented as the starting point of a conflict that ultimately led to the triumph of the Neogrammarians over the "old guard" - but this is an oversimplification. Both articles were somewhat iconoclastic - and both made arguments that are, by and large, still accepted and came to conclusions that are held as valid to this day. In one, Brugmann argues that the vowel system of Greek is more archaic than that of Sanskrit and PIE did not in fact have only one nonhigh vowel. In the other, he argues for the reconstruction of syllabic nasals for Proto-Indo-European, on the basis of correspondences like OE seofon, Gr hepta, La septem 'seven' or hund(red), Gr (he)katon, La centum. Both were extremely important discoveries for Indo-European linguistics, but the latter is interesting also in that, for the first time in the brief history of explicit linguistic reconstruction, it postulated a segment for the proto-language that is not attested in an unchanged form in any of the daughter languages (as opposed to the $a \sim 0 \sim e$ issue). And it is because of this that Curtius $(1885: 128)$ reacts in the following way:

\section{Even if one wished to allow syllabic $n$ for the proto-language, it would be a mistake to suppose that it existed in the Greek language... In my view syllabic $n$ can be justified for Greek only as a historical linguistic hieroglyph or, which is not much different, as an algebraic symbol. But let us not delude ourselves that with the postulation of this sound an actual fact of language history has come to light, which we would happily accept. ${ }^{3}$}

It is noteworthy that Curtius contrasts 'actual facts' with 'algebraic symbols' in this way and thus actually reprimands Brugmann for what he sees as unwarranted abstraction - when in fact Brugmann arrived

\footnotetext{
${ }^{3}$ Selbst wenn man das $n$ sonans für die Ursprache zugeben wollte, wäre es ein Fehler, seine Existenz auch für die Griechische Sprache zu behaupten... Das $n$ sonans hat meines Erachtens für das Griechische höchstens als sprachhistorische Hieroglyph oder, was davon nicht sehr verschieden ist, als algebraisches Zeichen, eine Art von Berechtigung. Aber verkennen wir nicht, dass mit der Aufstellung dieses Lautes zugleich ein wirkliches Factum der Sprachgeschichte zu Tage trat, das wir dankbar annehmen wollen.
} 
at this conclusion as a result of being very strictly methodical and principled and, of course, ingenious in reconstruction.

If we now turn to the treatment of morphology by the Neogrammarians, we see interesting and important developments there too. They fundamentally repudiated the grand evolutionary schemes of the Paleogrammarians, such as Schleicher's cycle of life, in the name of uniformitarianism. By repudiating these schemes they brought morphology down to earth, so to speak, but at the same time they connected morphology to psychology in a circular fashion (analogical change results from "attraction of concepts in the mind", cf. Paul 1880, but also provides the only evidence for it). Hermann Paul's discussions of analogy are very important and insightful, for instance in drawing the parallel between analogy as it works in historical change and analogy as a mechanism present in every single utterance that speakers make. But for the purposes of the present discussion the more important point is the relation between morphology and phonology, and this brings us to the principle of the exceptionlessness of sound change.

Much has been written about this principle in the course of a century and a half. It's been explained, refuted, defended and interpreted in many ways. It has been debated whether the principle was indeed a principle inherent in the inner workings of language change or a heuristic and methodological imperative, whether it was in a circular relation to analogical change or not, and so on. I will not rehearse the arguments but want to concentrate instead on one important consequence of the principle, which is somewhat neglected in the literature. It was said above that for the Paleogrammarians phonology was subordinated to morphology and if morphologicalfunctional parallels were found between related languages, the lack of systematic phonological correspondences did not deter them from establishing etymological connections between the units involved. With the Neogrammarians this came to an end. By insisting, in the name of exceptionlessness, that etymological identity can only be claimed if the forms under comparison fit into the system of phonological correspondences, they reversed the relationship between phonology and morphology, and from this time on morphological reconstruction was dependent on phonological reconstruction rather than vice versa. ${ }^{4}$

\footnotetext{
${ }^{4}$ For instance, when comparing Finnish kala- $t$ with Hungarian hala- $k$ 'fish PLURAL', the respective plural markers $t$ and $k$ cannot serve as the basis for reconstructing a common Proto-Uralic plural marker because there is no $t \sim k$ correspondence elsewhere between these languages (which, of course, does not per se mean that there was no plural marker in the proto-language). By contrast, the comparative markers in
} 
This extremely important principle became the cornerstone of comparative and historical linguistics, and it still is its cornerstone.

\section{De Saussure}

The last section of the paper is a brief note on Ferdinand de Saussure's Mémoire. De Saussure was a contemporary of the Neogrammarians and knew them personally, since he studied at Leipzig university in the late 1870 's. He also shared their interests, but they were not at all close to each other. His book, officially published in 1879 , when he was only 22 , is a real tour de force in the most problematic field of Ablaut theory; the logic of its argumentation is coherent and forceful, the whole work is based on an immense pool of data and it arrives at solid conclusions, though inevitably in certain respects it has been superseded. The fundamental issue is irregular ablaut patterns, where a long vowel is found where a short vowel should be and a short vowel is found where there should be no vowel, as in Gr ti-the-mi 'I put', E deed, do, vs. Gr thetos 'placed', La factum 'done', and so on. To put it very simply, de Saussure's solution was to hypothesise that the problematic long vowels were originally combinations of a short vowel and a consonantal element of some sort.

As has been said many times, the surprising strength of the argumentation derives from the fact that it is based on systemic considerations, which later came to be called internal reconstruction. It follows from the coherence of several patterns that the attested long vowels need to be reconstructed as sequences of a short vowel + something else. How did the Neogrammarians react to this? Basically they did not. They mostly ignored or dismissed de Saussure's findings, and the underlying reason appears to be that they missed the empirical underpinnings. This is clear from Brugmann's review of the book (1879). Brugmann asks in his review what evidence Saussure has for assuming that the long vowels in question had been in some earlier period, combinations of two distinct sounds. And his scepticism is understandable since the only Indo-European language in which these entities are attested as VC sequences is Hittite and Hittite was not yet known (it was not deciphered before the 1910's). I think that, at least to a certain extent, what the Neogrammarians found disturbing in Saussure's book was that it reminded them of the Paleogrammarianstyle scheme of presenting and analysing facts. On the surface,

Fi uude-mpi and $\mathrm{Hu}$ úja-bb 'newer' constitute legitimate etymological cognates because Hungarian voiced stops systematically correspond to Finnish nasal + voiceless stop sequences elsewhere too, e.g. Fi lintu 'bird' and Hu lúd 'goose'. 
Saussure's theory looked similar to Grimm's Kreislauf or Schleicher's vowel gradation, which the Neogrammarians were not sympathetic to. In retrospect, of course it is easy to say that they were wrong - though after a while they did incorporate his theory in their handbooks. But at the time when it was published, it did not fit into their positivistic approach, and so they shunned it.

\section{Conclusion}

I hope to have shown an interesting aspect of the shift of generations beginning in the 1870's. I have focused on two issues, one was the relation between phonology and morphology, the other the issue of abstractness vs. empiricism, which appears in a variety of forms. They both played a central role in the debates that shaped linguistics towards the end of the nineteenth century, and they did so with lasting consequences.

\section{Comments invited}

PiHPh relies on post-publication review of the papers that it publishes. If you have any comments on this piece, please add them to its comments site. You are encouraged to consult this site after reading the paper, as there may be comments from other readers there, and replies from the author. This paper's site is here:

http://dx.doi.org/10.2218/pihph.1.2016.1692

\section{Acknowledgements}

This paper is an edited and slightly modified version of a talk I gave at the 2015 Workshop on the History of Historical Phonology in Edinburgh. I am grateful to the audience at the Workshop for their comments on the talk.

\section{Author contact details}

András Cser

Pázmány Péter Catholic University

Faculty of Humanities and Social Sciences

Institute of English and American Studies

Egyetem u. 1., 2081, Piliscsaba

Hungary

cser.andras@btk.ppke.hu 


\section{References}

Bopp, Franz. 1816. Über das Conjugationssystem der Sanskritsprache in Vergleich mit jenem der griechischen, lateinischen, persischen und germanischen Sprache. Frankfurt: Windischmann.

Bopp, Franz. 1833-52. Vergleichende Grammatik des Sanskrit, Zend, Griechischen, Lateinischen, Lithauischen, Altslawischen, Gotischen und Deutschen. Berlin: Dümmler.

Brugmann, Karl. 1876a. Nasalis sonans in der indogermanischen Grundsprache. Studien zur Griechischen und Lateinischen Grammatik 9. 285-338.

Brugmann, Karl. 1876b. Zur Geschichte der stammabstufenden Declinationen. Erste Abhandlung: die Nomina auf -ar- und -tar-. Studien zur Griechischen und Lateinischen Grammatik 9. 361-461.

Brugmann, Karl. 1879. Review of Saussure 1879. Literarisches Centralblatt 773-4.

Curtius, Georg. 1885. Zur Kritik der neuesten Sprachforschung. Leipzig: Hirzel.

Grimm, Jacob. 1821. Deutsche Grammatik: Erster Teil (2nd edn). Göttingen: Dietrich'sche Buchhandlung.

Kempelen, Wolfgang von. 1791. Mechanismus der menschlichen Sprache, nebst Beschreibung einer sprechenden Maschine. Wien: Degen.

Kiparsky, Paul. 1974. From Paleogrammarians to Neogrammarians. In Dell Hymes (ed.) Studies in the history of linguistics, 331-345. Bloomington \& London: Indiana University Press.

Lass, Roger. 2016. Interpreting alphabetic orthographies: early Middle English spelling. In P. Honeybone \& Joseph Salmons (eds.) The Oxford handbook of historical phonology, 100-120. Oxford: Oxford University Press.

Morpurgo Davies, Anna. 1998. Nineteenth-century linguistics. London: Longman.

Murray, Robert W. 2015. The early history of historical phonology. In Patrick Honeybone \& Joseph Salmons (eds) The Oxford handbook of historical phonology, 11-31. Oxford: Oxford University Press.

Paul, Hermann. 1880. Prinzipien der Sprachgeschichte. Halle: Niemeyer.

Saussure, Ferdinand de. 1879. Mémoire sur le système primitif des voyelles dans les langues indo-européennes. Leipsick: Teubner.

Schlegel, Friedrich von. 1808. Über die Sprache und Weisheit der Indier. Heidelberg: Mohr \& Zimmer.

Pott, August Friedrich. 1833-36. Etymologische Forschungen auf dem Gebiete der Indogermanischen Sprachen. Lemgo: Meyer.

Schleicher, August. 1861. Compendium der vergleichenden Grammatik der indogermanischen Sprachen. Weimar: Böhlau. 
Sievers, Eduard. 1876. Grundzüge der Lautphysiologie zur Einführung in das Studium der Lautlehre der indogermanischen Sprachen. Leipzig: Breitkopf \& Härtel. 